\title{
Fluoride toothpaste supplemented with sodium hexametaphosphate reduces enamel demineralization in vitro
}

\author{
Danielle Mendes da Camara ${ }^{1}$ - Juliano Pelim Pessan ${ }^{1}$ - Tamires Melo Francati ${ }^{1}$. \\ José Antonio Santos Souza ${ }^{1}$ • Marcelle Danelon ${ }^{1}$. Alberto Carlos Botazzo Delbem ${ }^{1}$
}

Received: 28 April 2015 / Accepted: 30 December 2015 / Published online: 13 January 2016

(C) Springer-Verlag Berlin Heidelberg 2016

\begin{abstract}
Objective The aim of this study was to evaluate the effect of fluoride dentifrices combined with sodium hexametaphosphate (HMP) on enamel demineralization in vitro.

Material and methods Enamel bovine blocks were selected by initial surface hardness (SHi) and then divided into five experimental groups $(n=12)$ : placebo (without fluoride and without HMP); 1100 ppm F (1100F); and 1100F associated with HMP at $0.5 \%$ (1100HMP0.5\%), $1 \%$ (1100HMP1\%), and $2 \%$ of HMP (1100HMP2\%). Blocks were submitted to five $\mathrm{pH}$ cycles (demineralizing/remineralizing solutions) at $37^{\circ} \mathrm{C}$. After $\mathrm{pH}$ cycling, final surface hardness (SHf), percentage of surface hardness loss (\%SH), integrated differential hardness $(\Delta \mathrm{IH})$, integrated loss of subsurface hardness $(\triangle \mathrm{KHN})$, and enamel firmly bound fluoride $(\mathrm{F})$ were determined. Data were submitted to one-way ANOVA, followed by Student-Newman-Keuls test $(p<0.05)$.

Results Significant differences were observed among all groups regarding $\% \mathrm{SH}$ and $\triangle \mathrm{KHN} .1100 \mathrm{HMP} 1 \%$ promoted the lowest mineral loss among all groups $(p<0.001)$, and led to significantly lower demineralization in the deeper regions of the subsurface lesion when compared with the other HMPcontaining toothpastes $(p<0.001)$. Significantly higher mineral loss was observed for $1100 \mathrm{HMP} 2 \%$ when compared to the other fluoridated dentifrices, mainly in the outer part of the lesion $(p<0.001)$. Enamel $\mathrm{F}$ uptake was similar for $1100 \mathrm{~F}$ and
\end{abstract}

Alberto Carlos Botazzo Delbem

adelbem@foa.unesp.br

1 Department of Pediatric Dentistry and Public Health, Araçatuba Dental School, University Estadual Paulista (UNESP), Rua José Bonifácio 1193, 16015-050 Araçatuba, SP, Brazil
1100HMP $1 \%$ but significantly reduced for other HMP concentrations.

Conclusion The supplementation of a 1100-ppm F dentifrice with $1 \%$ HMP promoted a higher inhibitory effect against enamel demineralization when compared to a dentifrice containing the same amount of fluoride in vitro.

Clinical relevance This dentifrice could potentially be indicated to patients at high risk of caries.

Keywords Demineralization · Dental enamel ·

Polyphosphates $\cdot$ Fluorides $\cdot$ Dentifrices

\section{Introduction}

Dental caries still remains as the most common preventable chronic oral disease worldwide [1]. While the use of fluoride dentifrice is considered as a major reason for the remarkable decline in dental caries incidence and prevalence in developed countries [2], increasing the anticaries effects of conventional fluoride dentifrice (1100 ppm F) would be useful for further reducing caries incidence in the general population, but mainly in patients at high risk of caries. Since their introduction in the market, advances in technologies have improved the quality of the dentifrice not only regarding the availability of fluoride but also by combining fluoride with calcium and phosphate salts [3]. This has prompted research of new compounds that can provide essential elements for remineralization [4-7].

Sodium hexametaphosphate (HMP) is a cyclic inorganic phosphate with capacity to adsorb on enamel [7] and with strong tendency to form complexes with cations $[8,9]$. A recent in vitro study showed that HMP improved the effects of a low-fluoride dentifrice ( $250 \mathrm{ppm} \mathrm{F}$ ) [7]. As the ability of a condensed phosphate is proportional to the total number of phosphorus atoms [10], an appropriate ratio of HMP/F should 
be maintained to achieve an optimum anticaries effect [7]. These HMP/F proportions have been studied at concentrations of $250 \mathrm{ppm} F$ in the abovementioned study, but not for conventional dentifrice (1100 ppm F).

Therefore, the aim of this in vitro study was to evaluate the effect of different concentrations of HMP added to a dentifrice containing $1100 \mathrm{ppm} \mathrm{F}$ on bovine enamel demineralization in vitro. The null hypothesis was that dentifrice containing HMP presents the same anticaries effect as its counterpart without HMP.

\section{Material and methods}

\section{Experimental design}

Enamel blocks ( $4 \mathrm{~mm} \times 4 \mathrm{~mm}, n=60)$ of bovine incisors were stored in $2 \%$ formaldehyde solution $\mathrm{pH} 7.0$ for 30 days at room temperature [11]. The enamel surfaces of the blocks were sequentially polished and selected by surface hardness (SHi) test and randomly distributed (360 to 380 Knoop hardness $(\mathrm{KHN}) ; p=0.286)$ into five groups $(n=12)$, according to the following dentifrices: placebo (without fluoride and HMP); 1100 ppm F (1100F); and 1100F associated with HMP at $0.5 \%$ (1100HMP0.5\%), $1 \%$ (1100HMP $1 \%)$, and $2 \%$ (1100HMP2\%). Blocks were subjected to a pH-cycling regimen and treatment with dentifrice slurries twice/day. After $\mathrm{pH}$ cycling, final surface hardness (SHf), the percentage of surface hardness loss $(\% \mathrm{SH})$, integrated differential hardness $(\Delta \mathrm{IH})$, integrated loss of subsurface hardness $(\Delta \mathrm{KHN})$, and enamel firmly bound fluoride $(F)$ concentrations were determined.

\section{Dentifrice formulation and determination of fluoride and $\mathbf{p H}$}

The experimental dentifrices were prepared in a laboratory using the following ingredients: carboxymethylcellulose, sodium methyl- $p$-hydroxybenzoate, sodium saccharin, peppermint oil, glycerol, hydrated silica, and sodium lauryl sulfate [4, 12]. Different concentrations of HMP (Aldrich Chemistry, CAS 68915-31-1, UK) were used at $0.5,1$, and $2 \%$ (weight), with addition of fluoride (1100 ppm F) in the form of $\mathrm{NaF}$ (Merck, CAS 7681-49-4, Germany). The placebo dentifrice prepared without addition of F or HMP served as the negative control. A dentifrice with $1100 \mathrm{ppm} \mathrm{F}$ served as the positive control. F concentrations [11] and the $\mathrm{pH}$ [12] of the dentifrice were checked prior to the beginning of the study. Mean (SD) total and ionic fluoride concentrations $(n=3)$ for the placebo were $10.2(1.5)$ and $12.3(0.8)$, respectively. For the fluoridated toothpastes, mean (SD) TF concentrations were 1167.6 (45.4), 1117.4 (30.1), 1148.0 (15.7), and 1230.3 (20.6), respectively, for $1100 \mathrm{~F}, 1100 \mathrm{HMP} 0.5 \%, 1100 \mathrm{HMP} 1 \%$, and
1100HMP2\%. The corresponding values for IF were 1156.0 (79.0), 1080.4 (56.7), 1177.5 (63.3), and 1241.1 (7.3), respectively. The mean $(\mathrm{SD}) \mathrm{pH}$ values were placebo-7.4 (0.01), $1100 \mathrm{~F}-7.5(0.01), 1100 \mathrm{HMP} 0.5 \%-7.0(0.01)$, $1100 \mathrm{HMP} 1 \%-6.5(0.01)$, and 1100HMP2\%-6.2 (0.01).

\section{Dentifrice treatment and $\mathrm{pH}$ cycling}

The blocks were subjected to five $\mathrm{pH}$ cycles during 5 days (one cycle/day), and immersed in a fresh remineralizing solution for two additional days [13]. The dentifrice treatment was performed twice daily for $1 \mathrm{~min}$ using dentifrice suspended in deionized water $(1: 3 w / w)$. The treatments were performed when the samples were removed from the demineralizing solution $(6 \mathrm{~h} ; 2.0 \mathrm{mmol} / \mathrm{L}$ calcium and phosphate in $75 \mathrm{mmol} / \mathrm{L}$ acetate buffer, $\mathrm{pH} 4.7 ; 0.04 \mu \mathrm{g} \mathrm{F} / \mathrm{mL}, 2.2 \mathrm{~mL} / \mathrm{mm}^{2}$ ) and remineralizing solution $(18 \mathrm{~h} ; 1.5 \mathrm{mmol} / \mathrm{L}$ calcium; $0.9 \mathrm{mmol} / \mathrm{L}$ phosphate; $150 \mathrm{mmol} / \mathrm{L} \mathrm{KCl}$ in $0.02 \mathrm{~mol} / \mathrm{L}$ cacodylic buffer, $\mathrm{pH} 7.0 ; 0.05 \mu \mathrm{g} \mathrm{F} / \mathrm{mL}, 1.1 \mathrm{~mL} / \mathrm{mm}^{2}$ ).

\section{Enamel hardness analysis}

The surface hardness of the enamel was determined using a Shimadzu HMV-2000 microhardness tester (Shimadzu Corp., Kyoto, Japan) under a $25-\mathrm{g}$ load for $10 \mathrm{~s}$. Five indentations, spaced $100 \mu \mathrm{m}$ apart, were made in the center of the enamel block (SHi). After $\mathrm{pH}$ cycling, five indentations ( $\mathrm{SHf}$ ), spaced $100 \mu \mathrm{m}$ from the baseline indentations, were made to calculate the percentage of surface hardness loss $(\% \mathrm{SH}=[(\mathrm{SHf}$ $-\mathrm{SHi} / \mathrm{SHi}] \times 100)[4]$.

Blocks were then cross-sectioned, and half of each block was embedded in acrylic resin and gradually polished. One sequence of 14 indentations at different distances $(5,10,15$, $20,25,30,40,50,70,90,110,130,220$, and $330 \mu \mathrm{m}$ ) was made in the surface of the enamel in the central region. This was achieved using a Micromet 5114 hardness tester (Buehler, Lake Bluff, USA) with a Knoop diamond indenter under a 5-g load for $10 \mathrm{~s}$ [14] and the software program Buehler OmniMet (Buehler). Integrated hardness $(\mathrm{KHN} \times \mu \mathrm{m})$ for the lesion into sound enamel was calculated by the trapezoidal rule (GraphPad Prism, version 3.02) and subtracted from the integrated hardness for sound enamel to obtain the integrated area of the subsurface regions in enamel, which was named integrated loss of subsurface hardness $(\Delta \mathrm{KHN} ; \mathrm{KHN} \times \mu \mathrm{m})[15]$. To analyze the patterns of demineralization produced by addition of HMP, differential hardness profiles were calculated by subtracting the hardness values of the $1100 \mathrm{~F}$ group from those of the HMP groups (i.e., $1100 \mathrm{ppm} F$ dentifrice values minus the 1100HMP0.5\%, 1100HMP1\%, and 1100HMP2\% group values) at each depth. These differential profiles were then integrated over two depth zones in the lesion (zone A, 5$40 \mu \mathrm{m}$; zone B, 40-130 $\mu \mathrm{m}$ ) and underlying sound enamel to yield $\Delta \mathrm{IH}$ values [16]. 


\section{Fluoride analysis in enamel}

The fluoride present in enamel was determined as described by Weatherell et al. [17], as modified by Alves et al. [18]. One layer of each enamel block $(\sim 50 \mu \mathrm{m})$ was removed using a self-adhesive polishing disc (13-mm diameter, 400-grit silicon carbide, Buehler) and placed at the bottom of a polystyrene crystal flask (J-10; Injeplast, São Paulo, Brazil). A total of $1.0 \mathrm{~mL}$ of $1.0 \mathrm{~mol} / \mathrm{L} \mathrm{HCl}$ was added to the enamel powder; the mixture was agitated for $1 \mathrm{~h}$ and buffered with $1.0 \mathrm{~mL}$ of $1.0 \mathrm{~mol} / \mathrm{L} \mathrm{NaOH}[4,18]$. For fluoride analysis $\left(\mu \mathrm{g} / \mathrm{mm}^{3}\right)$, a specific electrode (Orion 9604) and reference microelectrode (Analyzer, São Paulo, Brazil) were connected to an ion analyzer (Orion 720plus) and calibrated with standards containing 0.5 to $8 \mu \mathrm{g} \mathrm{F} / \mathrm{mL}$. Aliquots of samples and total ionic strength adjustment buffer (TISAB) II were used at a 1:1 ratio (sample/TISAB II).

\section{Statistical analysis}

For the statistical analysis, Sigma Plot program (version 12.0) was used, with the significance level set at $5 \% . \% \mathrm{SH}, \Delta \mathrm{KHN}$, $\Delta \mathrm{IH}$, and $\mathrm{F}$ values were considered as variables in the enamel. The data were tested for normality (Shapiro-Wilk test) and homoscedasticity (Cochran). Data from the $\% \mathrm{SH}, \triangle \mathrm{KHN}$, and $\mathrm{F}$ values were homogenous and were subjected to oneway analysis of variance, followed by Student-NewmanKeuls test. The results $\Delta \mathrm{IH}$ were subjected to two-way analysis of variance (\%HMP and zone) followed by the StudentNewman-Keuls test.

\section{Results}

Significant differences were observed among all groups regarding $\% \mathrm{SH}$ and $\triangle \mathrm{KHN}$. For both variables, the lowest values were obtained after using $1100 \mathrm{HMP} 1 \%$, followed by $1100 \mathrm{HMP} 0.5 \%, 1100 \mathrm{~F}, 1100 \mathrm{HMP} 2 \%$, and placebo, as shown in Table $1(p<0.001)$. Similar amounts of $\mathrm{F}$ were observed for

Table 1 Mean (SD) values of hardness $(n=12)$ and fluoride analysis according to the groups

\begin{tabular}{llll}
\hline Groups & \multicolumn{3}{l}{ Variables } \\
\cline { 2 - 4 } & $\% \mathrm{SH}$ & $\Delta \mathrm{KHN}(\mathrm{KHN} \times \mu \mathrm{m})$ & $\mathrm{F}\left(\mu \mathrm{g} / \mathrm{mm}^{3}\right)$ \\
\hline Placebo & $-79.4^{\mathrm{a}}(6.6)$ & $10,954.5^{\mathrm{a}}(1565.1)$ & $1.98^{\mathrm{a}}(0.61)$ \\
$1100 \mathrm{~F}$ & $-41.2^{\mathrm{b}}(6.4)$ & $6298.5^{\mathrm{b}}(821.8)$ & $4.73^{\mathrm{b}}(0.88)$ \\
$1100 \mathrm{HMP} 0.5 \%$ & $-35.9^{\mathrm{c}}(4.2)$ & $3990.3^{\mathrm{c}}(1089.6)$ & $3.24^{\mathrm{c}}(1.10)$ \\
$1100 \mathrm{HMP} 1 \%$ & $-28.2^{\mathrm{d}}(5.5)$ & $2927.3^{\mathrm{d}}(788.5)$ & $4.08^{\mathrm{b}}(1.24)$ \\
$1100 \mathrm{HMP} \%$ & $-91.2^{\mathrm{e}}(5.8)$ & $8102.5^{\mathrm{e}}(1570.3)$ & $2.74^{\mathrm{a}, \mathrm{c}}(0.96)$ \\
\hline
\end{tabular}

Distinct superscript lowercase letters indicate statistical significance among groups in each variable (Student-Newman-Keuls test, $p<0.001$ ) the $1100 \mathrm{~F}$ and $1100 \mathrm{HMP} 1 \%$ groups $(p>0.05)$, but the addition of 0.5 and $2 \%$ HMP reduced the presence of fluoride in enamel when compared to the 1100F group $(p>0.01)$.

Differential hardness profiles (Fig. 1 and Table 2) showed different subsurface lesion patterns in relation to the $1100 \mathrm{~F}$ group. The addition of HMP $1 \%$ to $1100 \mathrm{~F}$ leads to significantly lower demineralization $(p<0.001)$ in the deeper regions of the lesion $(40-130 \mu \mathrm{m})$. On the other hand, the addition of HMP $2 \%$ to $1100 \mathrm{~F}$ promoted significantly higher mineral loss $(p<0.001)$, mainly in the outer regions of the lesion $(5-$ $40 \mu \mathrm{m})$.

\section{Discussion}

The present study showed that the addition of HMP at different concentrations to a dentifrice containing 1100 ppm F significantly altered their anticaries effects when compared to 1100F dentifrice without HMP, leading to the rejection of the study's null hypothesis. The concentrations of HMP tested were based on the HMP/F ratio from a previous study [7], which demonstrated that the addition of 0.5 or $1 \%$ HMP significantly increased the anticaries effect of a low-F dentifrice $(250 \mathrm{ppm} \mathrm{F})$, but HMP concentrations above $1 \%$ were detrimental.

HMP cannot be regarded as a phosphate source to react with tooth enamel, as it does not become spontaneously hydrolyzed $[8,19]$. This cyclic phosphate forms strong complexes with metal ions [19-22] and, in the oral environment, adsorbs to enamel surface and retains charged ions of $\mathrm{CaF}^{+}$ and $\mathrm{Ca}^{2+}$ by replacement of $\mathrm{Na}^{+}$in the cyclic structure, leading to a reticular formation [10] via $\mathrm{Ca}^{2+}$ binding to one or more HMP molecules. These can prove higher calcium availability during demineralization and remineralization processes as well as reduce the quick precipitation of calcium phosphate on the enamel surface [7].

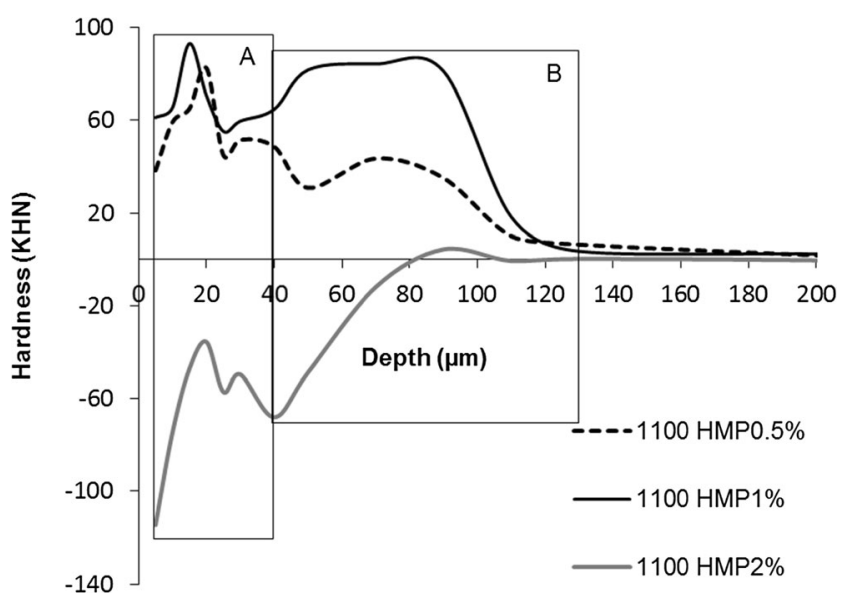

Fig. 1 Differential hardness profiles calculated by subtracting hardness values of the $1100 \mathrm{~F}$ group from HMP dentifrices in each depth (zone $A$ 5$40 \mu \mathrm{m}$, zone $B$ 50-130 $\mu \mathrm{m}$ ) 
Table $2 \Delta \mathrm{IH}$ values calculated for two zones in the enamel lesions according to the concentration of HMP

\begin{tabular}{lll}
\hline Groups & \multicolumn{1}{l}{$\Delta \mathrm{IH}$} \\
\cline { 2 - 3 } & Zone A $(5-40 \mu \mathrm{m})$ & Zone B $(40-130 \mu \mathrm{m})$ \\
\hline $1100 \mathrm{HMP} 0.5 \%$ & $1735.5^{\mathrm{a}, \mathrm{A}}(533.8)$ & $754.0^{\mathrm{a}, \mathrm{B}}(238.2)$ \\
$1100 \mathrm{HMP} 1 \%$ & $2037.0^{\mathrm{a}, \mathrm{A}}(368.5)$ & $1512.5^{\mathrm{b}, \mathrm{B}}(131.4)$ \\
$1100 \mathrm{HMP} \%$ & $-1699.5^{\mathrm{b}, \mathrm{A}}(718.5)$ & $-433.4^{\mathrm{c}, \mathrm{B}}(131.9)$ \\
\hline
\end{tabular}

Values denote means (SD). Distinct superscript lowercase letters indicate statistical significance among groups in each zone. Distinct uppercase letters indicate differences between zones A and B in each group (Student-Newman-Keuls test, $p<0.001$ )

The present data also showed that HMP affects the processes of enamel demineralization. Cross-sectional hardness analysis showed higher mineral content in the inner part of the lesion for specimens treated with $1100 \mathrm{HMP} 1 \%$ in comparison with fluoride dentifrice without HMP. $\triangle \mathrm{KHN}$ and $\% \mathrm{SH}$ (Table 1) observed in this study confirm the results of a previous study [7] that HMP reduces mineral loss deep in the enamel for groups 1100HMP0.5\% and 1100HMP $1 \%$ and confirm an appropriate ratio of $\mathrm{HMP} / \mathrm{F}$ should be maintained to achieve an optimum anticaries effect.

Although this hypothesis cannot be proved based on the study protocol employed, the above mentioned effect could be related to increases in the formation of neutral species $\left(\mathrm{CaHPO} 4^{0}\right.$ and $\mathrm{HF}^{0}$ ) during the demineralization and remineralization cycles, which have a greater coefficient of diffusion into the enamel in comparison with charged species [22]. It is also possible that HMP retains $\mathrm{H}^{+}$in its structure, which also reduces acid diffusion into the enamel, thus minimizing mineral loss. The proposed mechanism is also supported by comparing the results of a differential hardness profile between $1100 \mathrm{HMP} 1 \%$ and 1100F. The effects of the dentifrice with fluoride only (i.e., without HMP) were more marked at the outer parts of the lesion, which is in line with findings of previous studies [23, 24] and is regarded to be a large deposition of fluoride on the enamel surface. In the present study, however, HMP at 0.5 and $2 \%$ significantly reduced the amounts of enamel firmly bound fluoride when compared with 1100F, in line with previous reports using sodium trimetaphosphate as a phosphate source [16, 25]. On the other hand, similar amounts of firmly bound fluoride were observed for $1100 \mathrm{~F}$ and $1100 \mathrm{HMP} 1 \%$, indicating that HMP does not interfere with the diffusion of fluoride into the enamel depending on the appropriate molar ratio of the two active ingredients. Moreover and most importantly, it is noteworthy that the use of $1100 \mathrm{HMP} 1 \%$ promoted reductions of 32 and $53 \%$ in $\% \mathrm{SH}$ and $\triangle \mathrm{KHN}$ values, but this enhanced effect was not accompanied by an increase in enamel firmly bound fluoride. This aspect reinforces the concept that the mechanism of action of HMP-containing toothpastes is, in fact, different from that described for conventional (i.e., not supplemented) fluoride formulations, according to which the anticaries effect of the product is proportional to the amount of fluoride incorporated into enamel [26].

The addition of $2 \%$ HMP interfered with the absorption of fluoride in enamel, demonstrating that large percentage of HMP in the medium can supersaturate the enamel surface and further sequester calcium ions from hydroxyapatite due to its strong ability to complex metal ions [21]. Anbar et al. [27] showed the adsorption of polyphosphate is very fast and competes with the adsorption of ionic fluoride, which can reduce fluoride diffusion into enamel and lead to greater mineral loss. It is noteworthy that the addition of any compound to a fluoride dentifrice should not affect fluoride bioavailability, as verified in the present study. However, increasing the percentage of HMP reduced the $\mathrm{pH}$ of the dentifrice, but it was not possible to correlate this data with enamel mineral loss.

At first glance, the $\mathrm{pH}$-cycling models seem appropriate for the evaluation of the impact of new active ingredients on fluoridated toothpastes, as well as their association with other anticaries treatments. However, in vitro protocols present experimental design limitations as they did not address the impact of saliva/biofilm fluid composition on the interaction of the HMP with enamel. Given the in vitro model did not reproduce the intra-oral conditions, the results should be evaluated with caution and further assessed using an in situ caries model and clinical studies.

\section{Conclusion}

The addition of HMP1\% to a 1100-ppm F dentifrice promoted a higher inhibitory effect on enamel demineralization when compared to a dentifrice with the same fluoride concentration without HMP in vitro. A higher HMP concentration was not shown to be beneficial to the process.

Acknowledgments We thank Mrs. Maria dos Santos Fernandes (Laboratory of Pediatric Dentistry, Araçatuba Dental School, UNESP) for the laboratorial assistance in this study and CAPES (Brazil) for a scholarship granted to the first author.

\section{Compliance with ethical standards}

Funding This study was funded by CAPES-Brazil (scholarship to the first author).

Conflict of interest Ms. da Camara has received a scholarship from CAPES-Brazil. Prof. Delbem, Prof. Pessan, and Dr. Danelon have a patent request in Brazil (INPI) for "Formulations of topical agents containing 
phosphate/fluoride with effect against dental caries, dental erosion and tooth sensitivity."

Ethical approval This paper does not contain any studies with human subjects, so that no ethical approval was required.

Informed consent Same as above

\section{References}

1. Clarkson J, Watt RG, Rugg-Gunn AJ et al (2010) Proceedings: 9th World Congress on Preventive Dentistry (WCPD): "Community Participation and Global Alliances for Lifelong Oral Health for All," Phuket, Thailand, September 7-10, 2009. Adv Dent Res 22: 2-30

2. Marinho VCC, Higgins JP, Logan S, Sheiham A et al (2003) Topical fluoride (toothpastes, mouthrinses, gels, varnishes) for preventing dental caries in children and adolescents. Cochrane Database of Syst Rev 4:CD002782

3. Amaechi BT, van Loveren C (2003) Fluorides and non-fluoride remineralization systems. Monogr Oral Sci 23:15-26

4. Takeshita EM, Castro LP, Sassaki KT, Delbem AC (2009) In vitro evaluation of dentifrice with low fluoride content supplemented with trimetaphosphate. Caries Res 43:50-56

5. Do Amaral JG, Sassaki KT, Martinhon CC, Delbem AC (2013) Effect of low-fluoride dentifrices supplemented with calcium glycerophosphate on enamel demineralization in situ. Am J Dent 26: $75-80$

6. Zaze AC, Dias AP, Sassaki KT, Delbem AC (2014) The effects of low-fluoride toothpaste supplemented with calcium glycerophosphate on enamel demineralization. Clin Oral Investig 18:1619-1624

7. da Camara DM, Miyasaki ML, Danelon M, Sassaki KT, Delbem AC (2014) Effect of low-fluoride toothpastes combined with hexametaphosphate on in vitro enamel demineralization. J Dent 42:256-262

8. Castellini E, Lusvardi G, Malavasi G, Menabue L (2005) Thermodynamic aspects of the adsorption of hexametaphosphate on kaolinite. J Colloid Interface Sci 292:322-329

9. Andreola F, Castellini E, Manfredini T, Romagnoli M (2004) The role of sodium hexametaphosphate in the dissolution process of kaolinite and kaolin. J Eur Ceram Soc 24:2113-2124

10. van Wazer JR, Campanella DA (1950) Structure and properties of the condensed phosphates. IV. Complex ion formation in polyphosphate solutions. J Am Chem Soc 72:655-663

11. Delbem AC, Bergamaschi M, Rodrigues E, Sassaki KT, Vieira AE, Missel EM (2012) Anticaries effect of dentifrices with calcium citrate and sodium trimetaphosphate. J Appl Oral Sci 20:94-98

12. Moretto MJ, Magalhães AC, Sassaki KT, Delbem AC, Martinhon CC (2010) Effect of different fluoride concentrations of experimental dentifrices on enamel erosion and abrasion. Caries Res 44:135140
13. Vieira AE, Delbem AC, Sassaki KT, Rodrigues E, Cury JA, Cunha $\mathrm{RF}$ (2005) Fluoride dose response in $\mathrm{pH}$-cycling models using bovine enamel. Caries Res 39:514-520

14. Delbem AC, Danelon M, Sassaki KT, Vieira AE, Takeshita EM, Brighenti FL et al (2010) Effect of rinsing with water immediately after neutral gel and foam fluoride topical application on enamel remineralization: an in situ study. Arch Oral Biol 55:913-918

15. Spiguel MH, Tovo MF, Kramer PF, Franco KS, Alves KM, Delbem AC (2009) Evaluation of laser fluorescence in the monitoring of the initial stage of the de-/remineralization process: an in vitro and in situ study. Caries Res 43:302-307

16. Danelon M, Takeshita EM, Peixoto LC, Sassaki KT, Delbem AC (2014) Effect of fluoride gels supplemented with sodium trimetaphosphate in reducing demineralization. Clin Oral Investig 18:1119-1127

17. Weatherell JA, Robinson C, Strong M, Nakagaki H (1985) Microsampling by abrasion. Caries Res 19:97-102

18. Alves KM, Pessan JP, Brighenti FL, Franco KS, Oliveira FA, Buzalaf MA et al (2007) In vitro evaluation of the effectiveness of acidic fluoride dentifrices. Caries Res 41:263-267

19. Choi IK, Wen WW, Smith RW (1993) Technical note the effect of a long chain phosphate on the adsorption of collectors on kaolinite. Miner Eng 6:1191-1197

20. Kura G, Ohashi S, Kura S (1974) Complex formation of cyclic phosphate anions with bivalent cations. J Inorg Nuc Chem 36: 1605-1609

21. Changgen L, Yongxin L (1983) Selective flotation of scheelite from calcium minerals with sodium oleate as a collector and phosphates as modifiers. II. The mechanism of the interaction between phosphate modifiers and minerals. Int J Min Process 10:219-235

22. Cochrane HJ, Saranathan S, Cai F, Cross KJ, Reynolds EC (2008) Enamel subsurface lesion remineralisation with casein phosphopeptide stabilised solutions of calcium, phosphate and fluoride. Caries Res 42:88-97

23. Altenburger MJ, Schirrmeister JF, Wrbas KT, Klasser M, Hellwig E (2008) Fluoride uptake and remineralisation of enamel lesions after weekly application of differently concentrated fluoride gels. Caries Res 42:312-321

24. Attin T, Lennon AM, Yakin M, Becker K, Buchalla W, Attin R, Wiegand A (2007) Deposition of fluoride on enamel surfaces released from varnishes is limited to vicinity of fluoridation site. Clin Oral Investig 11:83-88

25. Manarelli MM, Delbem AC, Lima TM, Castilho FC, Pessan JP (2014) In vitro remineralizing effect of fluoride varnishes containing sodium trimetaphosphate. Caries Res 48:299-305

26. Afonso RL, Pessan JP, Igreja BB, Cantagallo CF, Danelon M, Delbem AC (2013) In situ protocol for the determination of doseresponse effect of low-fluoride dentifrices on enamel remineralization. J Appl Oral Sci 21:525-532

27. Anbar M, Farley EP, Denson DD, Maloney KR (1979) Localized fluoride release from fluorine-carrying polyphosphonates. J Dent Res 58:1134-1145 